\title{
Technology Development Analysis on Low Carbon for Power of Heavy-Duty Commercial Vehicle
}

\author{
Jiangwei Liu ${ }^{1}$ Jun $\mathrm{Li}^{2} \cdot$ Yongjun Wang ${ }^{1}$ (D) Dalu Dong ${ }^{1} \cdot$ Yansheng Yin ${ }^{1} \cdot$ Huayu Jin ${ }^{1} \cdot$ Shijie Sun $^{1} \cdot$ Huili Dou $^{1}$. \\ Yanbo Shi ${ }^{1} \cdot$ Lei Fu' ${ }^{1} \cdot \mathrm{Fei} \mathrm{Ge}^{1}$
}

Received: 13 November 2018 / Accepted: 24 January 2019 / Published online: 19 February 2019

(C) The Author(s) 2019

\begin{abstract}
Commercial vehicle industry worldwide is facing challenges from environmental pressures, stringent limits of $\mathrm{CO}_{2}$ emission, governmental regulations as well as ever-increased customer demands. This paper analyzes the above-mentioned challenges, especially in China, including the potential improvement to increase the brake thermal efficiency (BTE), with five levels of BTE proposed, ranging from current 45 to $60 \%$ in future, corresponding to China fuel consumption regulation (CFCR) in different phases. The authors also proposed the technology roadmaps to meet the upcoming CFCR3 and CFCR4; finally, the authors draw the conclusions to conform with ever-stringent regulation in China.
\end{abstract}

Keywords Heavy-duty diesel engine (HDDE) $\cdot$ Low carbon $\cdot$ Fuel consumption

\section{Introduction}

Environmental issues are attracting increasing attention worldwide, especially the problem of climate change associated with carbon emissions. International communities have reached the agreement to limit the global average temperature rise within $2{ }^{\circ} \mathrm{C}$ and accumulated carbon dioxide emission ever within 3.2 trillion tons in the future. In 2015, 195 countries signed the Paris Agreement, which came into effect in 2016 to limit the carbon emission. Chinese government committed to peak carbon emission in 2030, to reduce the carbon emission by $60-65 \%$ per unit GDP from the level of 2005.

As shown in Fig. 1 [1], $\mathrm{CO}_{2}$ emissions from global road transport account for $17 \%$ of the total emissions, and $\mathrm{CO}_{2}$ emission shares of $28 \%, 25 \%$ and $16 \%$ are observed for the USA, Europe and Japan. In China, the proportion of $\mathrm{CO}_{2}$ emissions due to road transport relative to the total amount of emissions increased from $4.6 \%$ in 2005 to $7 \%$ in 2015 , because of the greater number of vehicles operating in the

Yongjun Wang

wangyj_qy@faw.com.cn

1 China FAW Group Corporation Limited, Changchun 130000, China

2 Tsinghua University, Beijing 100084, China country [2]. It is predicted that $\mathrm{CO}_{2}$ emission from diesel vehicles will continue to increase from 2020 to 2035 [2], which will result in an additional challenge to the target of $\mathrm{CO}_{2}$ emission abatement.

As shown in Fig. 2 [3], commercial vehicle $\mathrm{CO}_{2}$ emissions account for $53 \%$ of the total $\mathrm{CO}_{2}$ emission from automobiles in China, representing approximately 300 million tons due to operational service in 2015. The overall $\mathrm{CO}_{2}$ emission from commercial vehicles during its life cycle can be broken down into two parts: $75 \%$ emitted during use of the vehicle and 25\% resulting from other sources [3], including material processing, recycling, assembly and maintenance.

Because of the high $\mathrm{CO}_{2}$ emissions from heavy-duty vehicles (HDVs), many countries are currently considering fuel consumption regulations aimed at motivating companies to produce clean, energy-efficient vehicles (see Fig. 3). China and the USA both have fuel consumption standards at present, while the European Union plans to implement a $\mathrm{CO}_{2}$ monitoring and reporting mechanism by 2019 , with $\mathrm{CO}_{2}$ limits taking effect around 2022. The current China Fuel Consumption Regulation (CFCR3 or GB 30510-2018) for HDVs sets limits for vehicle fuel consumption based on the China World Transient Vehicle Cycle (C-WTVC) [4]. CFCR3 will take effect in 2019, while the subsequent CFCR4 will likely come into force in 2024. Each CFCR stage requires an approximately $15 \%$ 
$\mathrm{CO}_{2}$ ratio of road transportation in world

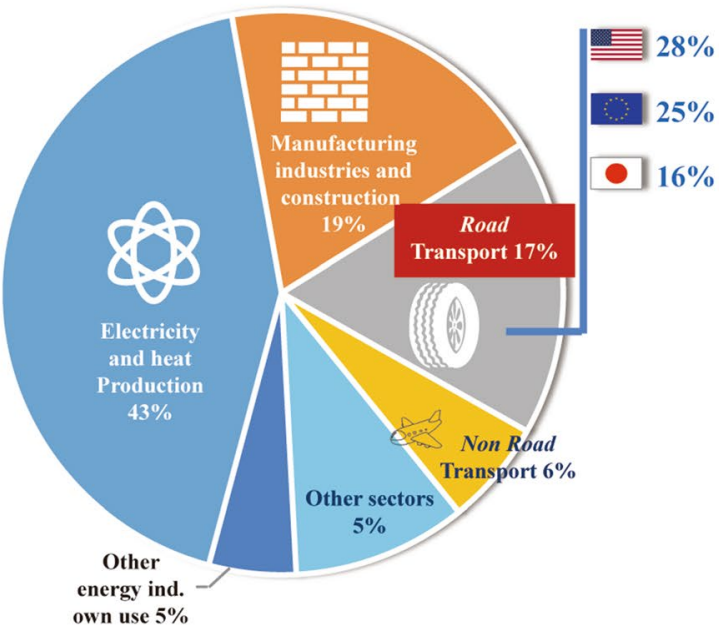

$\mathrm{CO}_{2}$ ratio of road transportation in China

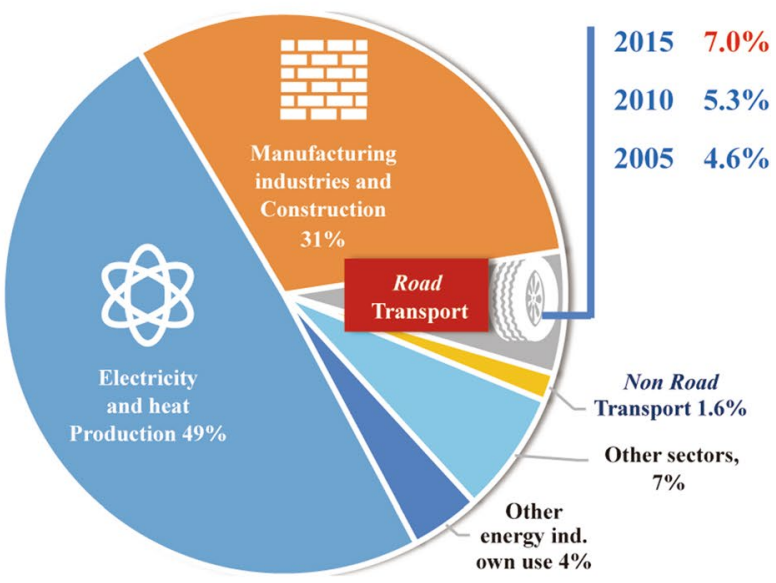

Fig. $1 \mathrm{CO}_{2}$ emissions from road transportation worldwide and in China [1]

Fig. $2 \mathrm{CO}_{2}$ emissions from road transportation in China
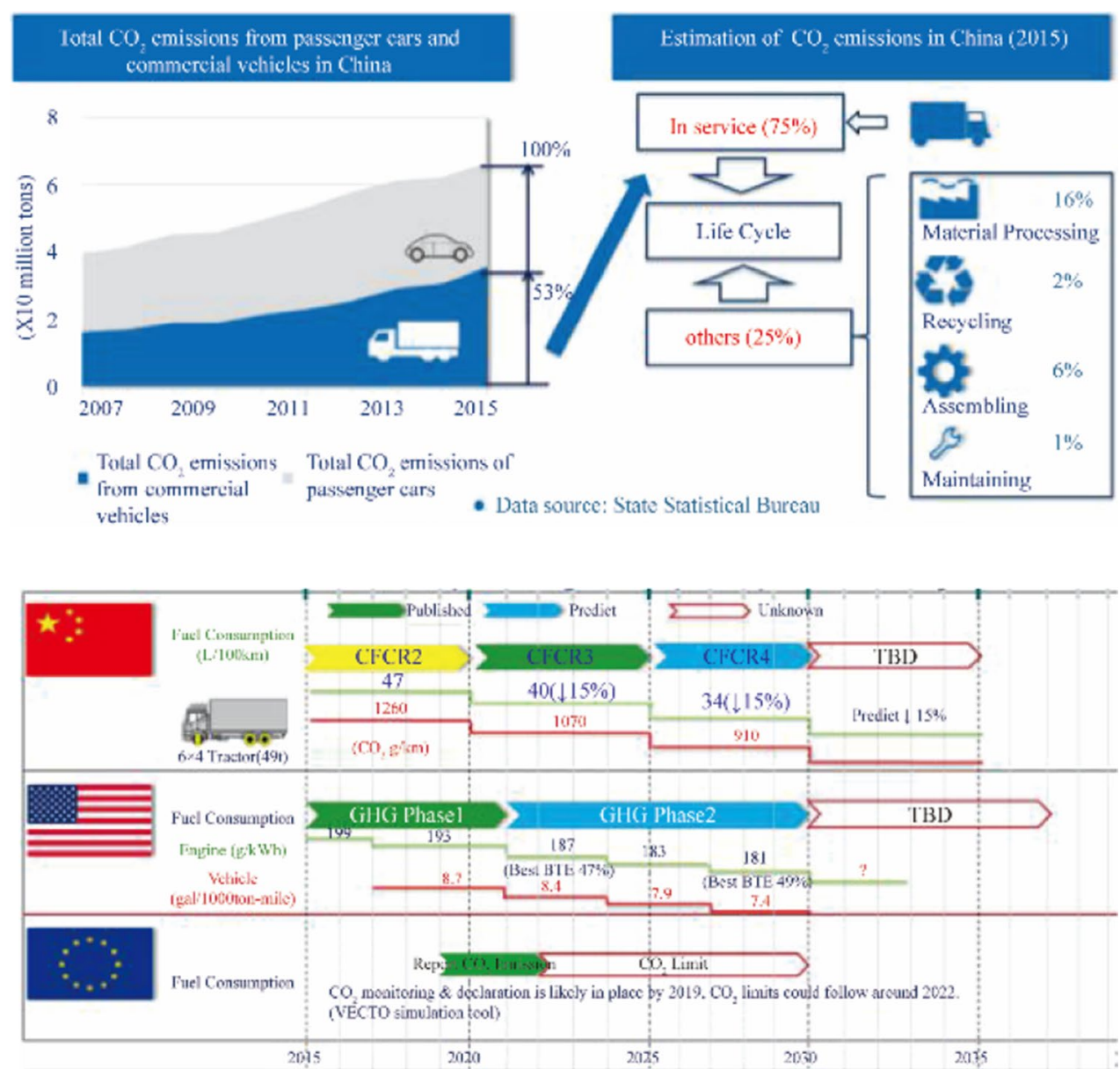

Fig. 3 A comparison of global HDDE emissions regulations reduction in fuel consumption compared with the previous one (Fig. 4). CFCR1 was drafted in 2009 without fuel consumption limits, while CFCR2 was updated in
2014 and contained limits, and the current CFCR3 was updated in 2018 with more stringent limits. The US fuel consumption regulations specify $\mathrm{CO}_{2}$ emission limits for 


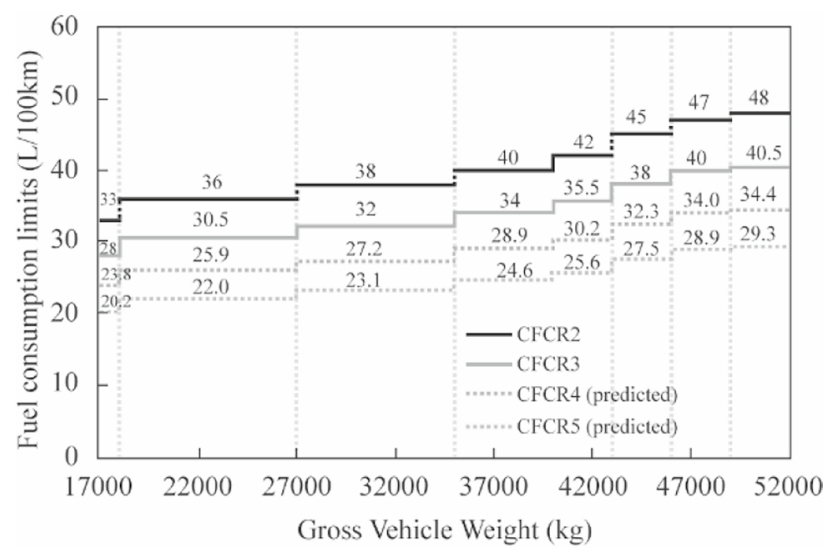

Fig. 4 CFCR limits for HDVs

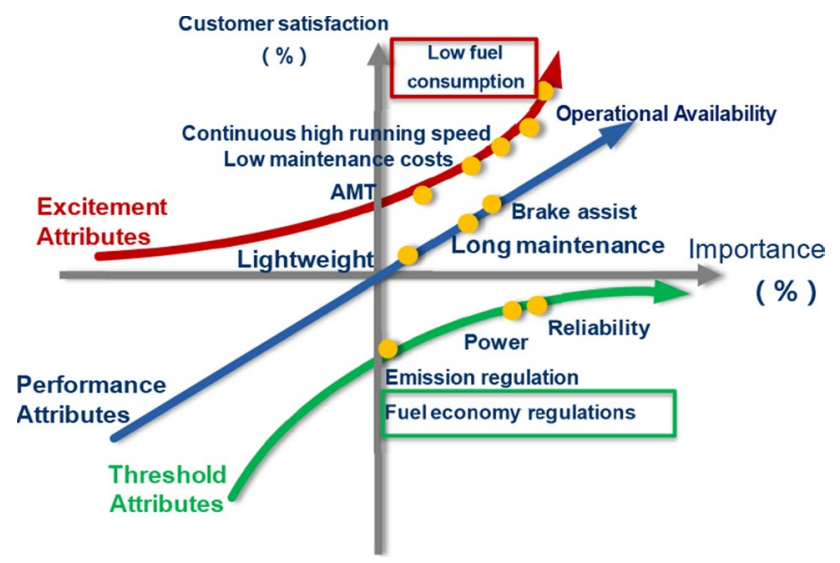

Fig. 5 A Kano model for HDVs based on FAW's customer survey

both vehicles and engines. Based on engine $\mathrm{CO}_{2}$ emission from US regulation, the best brake thermal efficiency (BTE) values are required to reach $47 \%$ in 2021 and $49 \%$ in 2027, which represents a significant challenge for diesel engines (Fig. 3). The CFCR sets limits for $\mathrm{CO}_{2}$ emissions based on vehicle fuel consumption (in $\mathrm{g} / 100 \mathrm{~km}$ ). The US
EPA and National Highway Traffic Safety Administration (NHTSA) regulate $\mathrm{CO}_{2}$ emissions and fuel consumption, respectively, and their limits are not correlated with Chinese regulations. Engine fuel consumption limits are on the basis of gal/100 hp-h, which must be translated to a minimum engine fuel consumption.

From the customer's perspectives, it is estimated that the fuel consumption is the largest part of total cost of ownership (TCO) for commercial vehicle, accounting for 35\%, based on a customer survey conducted by China FAW. The Kano model in Fig. 5 shows that fuel consumption regulations are a so-called threshold attribute in the case of HDVs, while low fuel consumption is an excitement attribute. Thus, both are primary considerations of commercial vehicle original equipment manufacturers (OEMs) when developing strategies and technology roadmaps for $\mathrm{CO}_{2}$ abatement.

\section{Potential Improvements in HDDE BTE}

Increasing the efficiency of heavy-duty diesel engines (HDDEs) is the most important aspect of reducing fuel consumption and hence of reducing $\mathrm{CO}_{2}$ emissions. The maximum BTE value that can be obtained from a slider-crank engine is approximately $60 \%$ based on the present-day technologies (see Fig. 6), assuming that cost is not a constraint. Previous work by the authors has shown that the theoretical efficiency limit for an HDDE is approximately $69.2 \%$ and that the main energy loss results from exhaust gases, accounting for about $30.8 \%$ of the total energy released by fuel combustion. With the loss of heat transfer deducted, or $13 \%$ of energy loss, the gross indicated efficiency is brought down to $57.5 \%$. With deduction of pumping loss of $1 \%$, net indicated efficiency is brought down to $56.5 \%$. With further deduction loss of $2 \%$ for friction plus accessory, brake efficiency is further reduced to $54.5 \%$, and only with the positive increase in efficiency of $5.5 \%$ for waste heat recovery, can brake efficiency be raised to $60 \%$.
Fig. 6 Technology array with BTE vs Energy losses

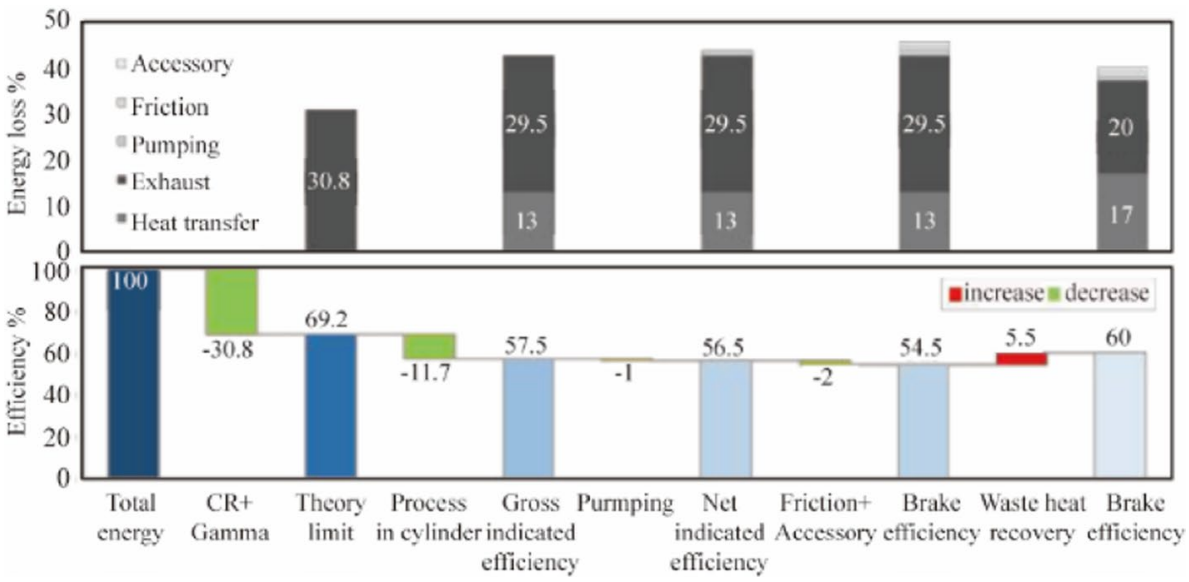




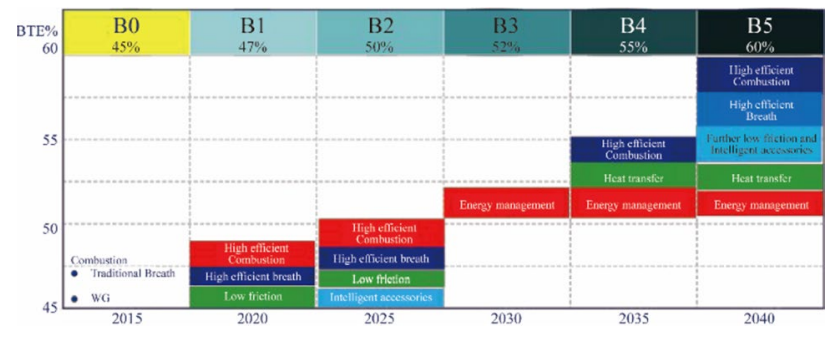

Fig. 7 A roadmap to increased efficiency levels

Globally, OEMs are striving to obtain a BTE of 50\% solely on the basis of improved engine designs, and BTE values of 55\% are anticipated following the adoption of Rankine cycle technology.

Based on B0 of BTE 45\%, the author defines five levels targeting from BTE 47-60\% (Fig. 7). Level B1 in 2020 BTE is expected to reach $47 \%$, with $2 \%$ increase from technology adoption of combustion and the breath process optimization as well as low friction. In 2025, the BTE is expected to reach $50 \%$ at level B2, with more efforts for heat transfer and intelligent accessories based on level 1. Beyond BTE 50\%, technologies of exhaust heat recovery have to be adopted, such as Rankine cycle [5]. In the case of HDVs, the Rankine cycle is the most applicable commercial technology for waste heat recovery [6]. The biggest challenge at present is to realize BTE of 50\% without implementation of such technology.

\section{Technology Roadmap for Low-Carbon HDDEs having a BTE of $50 \%$}

CFCR3 requires a $15 \%$ reduction in fuel consumption compared with CFCR2. The engine will contribute 35\%, which needs fuel saving about $5 \%$ for engine. Currently HDDE BTE in general is $43-45 \%$, and to meet CFCR3 and keep product competitive in market, BTE of $47 \%$ is a challenging target.

HDDE has the potential to meet BTE of $47 \%$ based solely on improvements to the engine, while maintaining a reasonable TCO. OEMs should consider that lean combustion design is the key to engine optimization, so as to avoid large investments associated with other structural redesigns. For future CFCR4, various innovative technologies intended to reduce fuel consumption by combustion optimization are presented herein, which may allow future vehicles to meet the requirements of CFCR4.

Figure 8 shows the proportional energy distribution from tank to wheel and indicates that heat transfer and exhaust gases consume $19 \%$ and $28 \%$ of the total energy, respectively. There are two pathways to increasing the BTE from 45 to $50 \%$ (Fig. 9). One involves optimization of the combustion and breath processes, while the other consists of

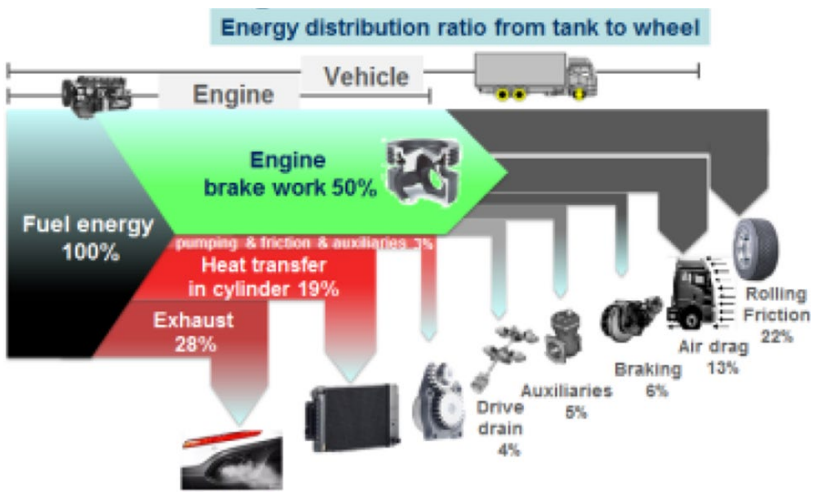

Fig. 8 Energy distribution throughout a vehicle wheels

reducing the losses due to friction and accessories. In addition, various control strategies and efficient post-processing technologies to achieve efficient post-processing efficiency are also necessary to support the implementation of efficient combustion.

\subsection{Optimization of the Combustion Process}

There are three criteria involved in selecting new technologies for implementation: effectiveness, benefit and competitiveness. The latter can in turn be categorized into differentiation, innovation and charming characteristic. Reductions in losses due to friction and accessories or in threshold characteristics are necessary, so combustion optimization should contribute to more than $80 \%$ of the fuel saving to achieve the BTE target. Improvements in the fuel injection system, combustion chamber and turbocharging are also being considered by the China FAW.

There are four technologies available for optimization of combustion process, i.e., fuel injection and supply, combustion chamber shape optimization, optimization of initial flow in cylinder, charge quality and composition as well as compression and expansion [7].

Fuel injection and supply system have the potential to increase the BTE by $1.5 \%$, which includes variable injection

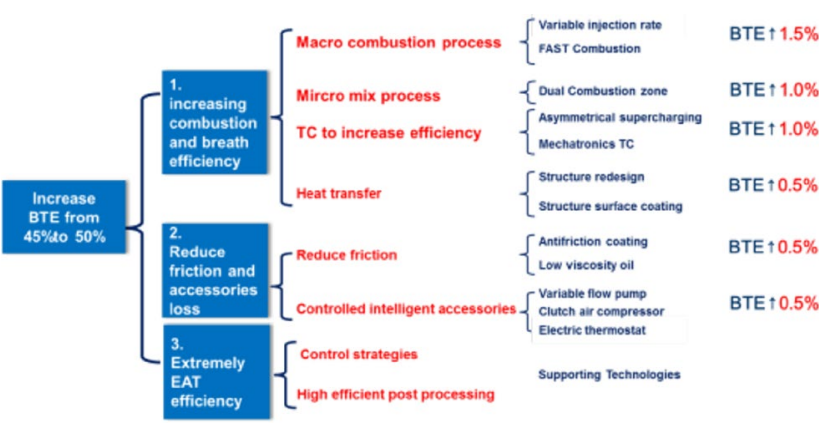

Fig. 9 FAW roadmap to meet BTE 50\% 


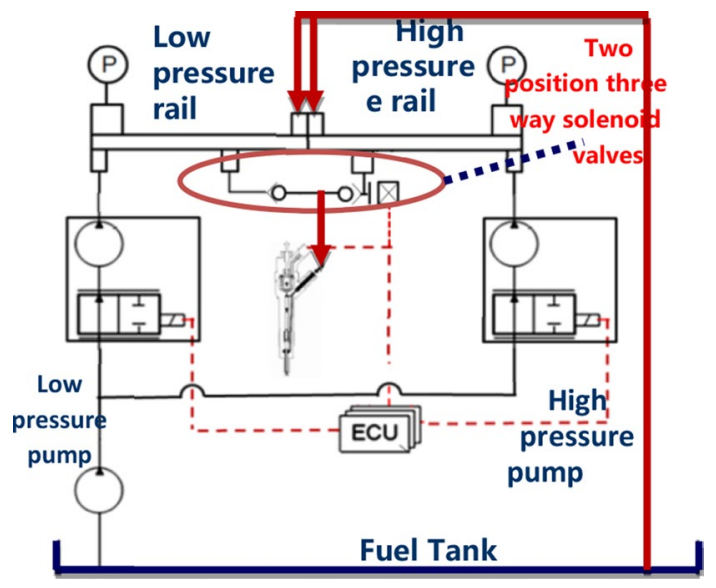

Fig. 10 A schematic showing the FAW FDCR concept

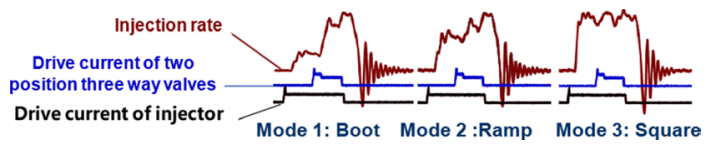

Fig. 11 FDCR injection modes

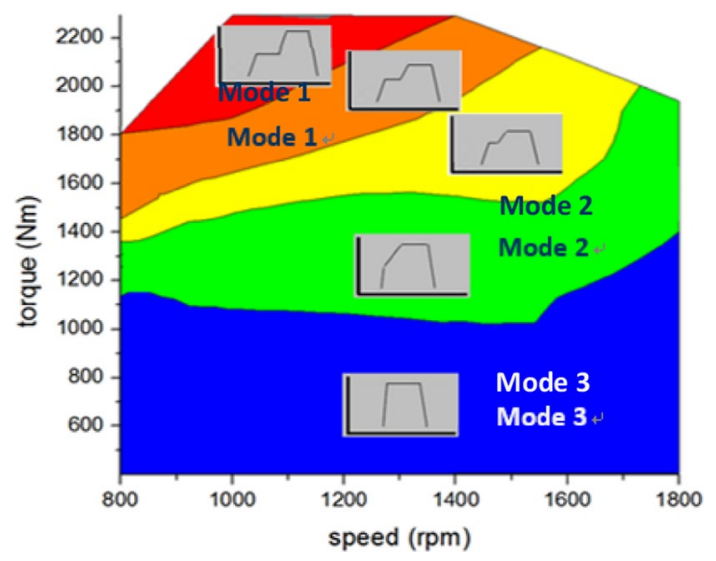

Fig. 12 An engine mapping with three injection modes

rates, rapid combustion and optimization of the injection timing and pressure. Combination of combustion chamber shape optimization and optimization of initial flow in cylinder may have $1.0 \%$ of BTE gain [8].

Asymmetrical supercharging plus electromechanical turbocharger will increase $1 \%$ of BTE in terms of charging.

China FAW has developed the FAW Double Common Rail (FDCR) system for fuel injection system (Fig. 10). This technology consists of dual common rails (with high and low internal pressures) and a two-position, three-way solenoid valve, allowing engine mapping with three injection rates. Figure 11 shows the test results obtained using
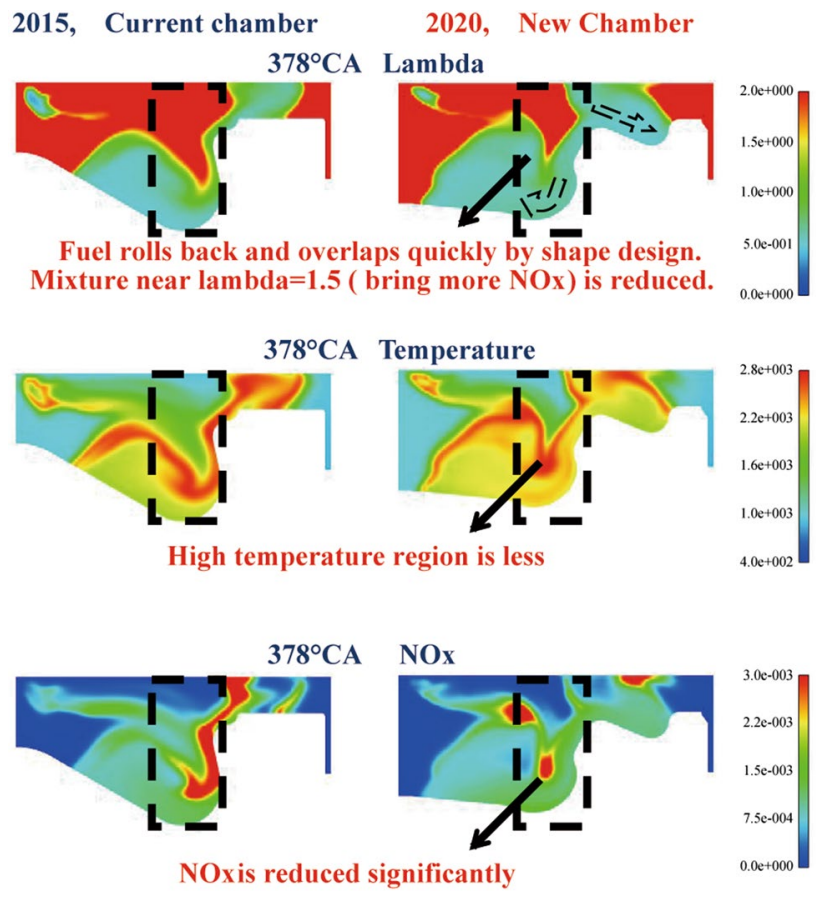

Fig. 13 Combustion simulation results

different injection modes. These data demonstrate changes in the delta pressure values and high pressure/low pressure timing, which lead the system to produce a boot for mode 1 , ramp for mode 2 and square for mode 3 of different injection rates. These modes are in agreement with the engine map requirement in Fig. 12.

Redesigning the combustion chamber can significantly reduce the generation of $\mathrm{NO} x$, as shown in the simulation results in Fig. 13. Fully utilizing both the available space and oxygen in the cylinder improves combustion while lowering the combustion temperature, thus inhibiting the formation of $\mathrm{NO} x$.

The spatial and temporal zone control strategies were developed, and evaluation criteria were set up. Consequently, the air utilization rate and high-temperature region were optimized so as to ensure properly distributed combustion. The associated experimental results demonstrate that a $2-5 \mathrm{~g} / \mathrm{kWh}$ reduction in the brake specific fuel consumption can be achieved, while maintaining the same NO $x$ level.

China FAW has also reported innovation in turbocharging technology, with special designs currently under development. The main purpose of the turbocharge system is to recover as much exhaust energy as possible, while increasing the compressor efficiency. At low to medium speeds, small volute increases pulse supercharging, produces high 


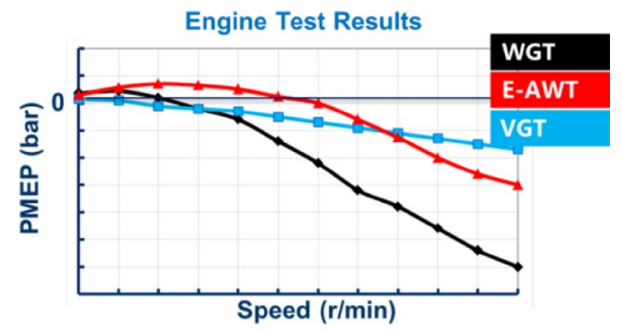

Fig. 14 Engine test results

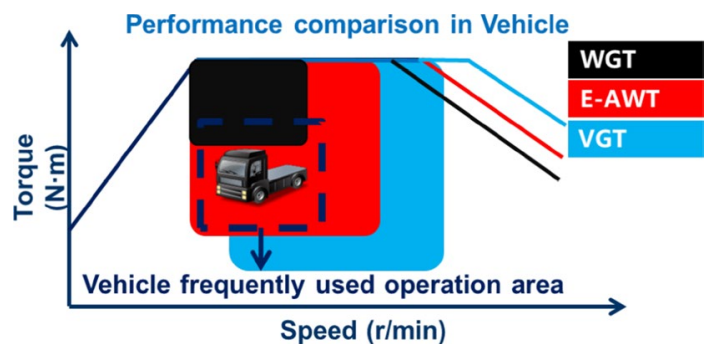

Fig. 15 Performance comparison in vehicle

backpressure to drive exhaust gas recirculation. At high speeds, the balance valve opens, such that exhaust gas flows along large volute so as to improve constant pressure supercharging while decreasing the pump mean effective pressure (PMEP) [9]. Innovative turbocharging technology should also reduce costs and complexity while increasing reliability. Figure 14 presents plots of PMEP data obtained using waste gate turbocharger (WGT), electronic controlled asymmetrical waste gate turbocharger (E-AWT) and variable geometry turbocharger (VGT) technologies. These designs are seen to reduce the PMEP, which in turn increases engine efficiency, while increasing fuel economy in the most frequently used driving area (see Fig. 15).

\subsection{Reduction in Losses}

The potential approaches to reducing friction losses include antifriction coatings and low-viscosity oil. In addition, the energy consumption of various accessories, including the variable oil pump, clutch air compressor and electric thermostat, could all be lowered. The use of low-viscosity oil in conjunction with a variable rate oil pump is projected to increase the BTE by $0.5 \%$.

\section{The Correlation of Energy Consumption with Fuel Combustion}

Fuel reduction from engine operation point of view is considered. Both hybrid electric vehicle (HEV) and intelligent and connected vehicle (ICV) technologies are important means of reducing fuel consumption, while nature gas engine will develop fast as it is one of the effective ways from alternative fuel point of view for $\mathrm{CO}_{2}$ emission reduction. In addition, waste heat recovery can greatly increase efficiency, depending on the vehicle operating conditions. Because various running modes require different system designs, OEMs must improve their system design capabilities in a cooperative manner with vehicle design.

With the C-WTVC, the $\mathrm{CO}_{2}$ emission from heavy commercial natural gas vehicles is $7.1 \%$ lower than those from diesel vehicles. As such, natural gas is the most suitable lowcarbon fuel for heavy-duty commercial vehicles [10]. With the tractor express conditions in China, the $\mathrm{CO}_{2}$ emissions from liquid natural gas (LNG) vehicles are also approximately $5.9 \%$ less than those generated by diesel vehicles. Thus, meeting the low-carbon and environmental protection requirements under the green development principle of the Chinese government may require the increased adoption of heavy commercial natural gas vehicles.

Reducing the fuel consumption for HEVs is greatly dependent on the operational mode because frequent start and stop modes have more potential for energy recovery. In the C-WTVC vehicle testing cycle, buses and delivery vehicles demonstrated greater potential for lower fuel usage, with savings of up to $7 \%$. Based on balancing weight and efficiency, hybrid vehicles are evidently best suited to long haul transportation. Other future technology for reducing $\mathrm{CO}_{2}$ emissions in conjunction with ICV is predictive cruise control. However, the benefit of this technology depends on the grade value and frequency of the roads being travelled, with hilly terrain up and downhill resulting in a 3-5\% fuel saving on average. Platooning based on technology of Cooperative Adaptive Cruise Control (CACC) could also drastically reduce air drag, thus lowering fuel usage by an additional $4-7 \%$.

\section{Conclusions}

Upcoming $\mathrm{CO}_{2}$ emissions regulations in China represent a challenge that will greatly affect the development of commercial vehicle technologies and products. This legislation will have a significant impact on the automotive industry over the next decade. In addition to the CFCR 3 and CFCR4 requirements, another key driver for $\mathrm{CO}_{2}$ emissions 
abatement will be competition to develop more fuel-efficient vehicles for both global and domestic markets.

Different technologies will be adopted to meet these challenges, depending on the market segment. China FAW considers that HDDE will realize maximum BTE, but those improvements in fuel and hybrid technologies will also be achieved. Other innovative technologies related to green vehicles are necessary, including intelligent, connected transportation, and will likely be adopted by the Chinese automobile industry to further reduce $\mathrm{CO}_{2}$ emissions.

Based on the review detailed herein, the following conclusions can be drawn.

1. Significant changes in customer demands, regulations and policies are anticipated over the next decade in China.

2. The most important driver for future vehicle design will be the fuel consumption, which is both a so-called threshold and excitement attribute, and a regulatory requirement.

3. China FAW developed BTE levels up to $60 \%$, and with detailed potential analysis based on energy distribution from tank to wheel, FAW proposed that the greatest challenge lies in creating engine concept without adoption of Rankine cycle technology to meet BTE 50\%.

4. China FAW developed FDCR technologies, including injection modes, combustion chamber redesign and E-ATW, to meet the BTE goal of $47 \%$.

5. ICE and NEV powertrain platforms will be necessary to meet the new regulations. The following points should be considered.

(a) Continued research and development of ICE and NEV powertrain platforms will be required.

(b) Technology roadmaps for ICE powertrain add-on strategies have been developed, involving an NEV powertrain cut-down strategy. (c) The pace of new technology upgrades should be controlled based on just-in-time management principles.

(d) Reducing costs while implementing upgrades to core technologies will necessitate the use of lean design.

Open Access This article is distributed under the terms of the Creative Commons Attribution 4.0 International License (http://creativeco mmons.org/licenses/by/4.0/), which permits unrestricted use, distribution, and reproduction in any medium, provided you give appropriate credit to the original author(s) and the source, provide a link to the Creative Commons license, and indicate if changes were made.

\section{References}

1. IEA: $\mathrm{CO}_{2}$ Emission from fuel combustions. 2008-2016

2. Zhang, X., Wang, Y., Li, J., et al.: Systems engineering study on the decarbonization of automobiles in China. Strateg. Study CAE 20(1), 1-7 (2018)

3. State Statistical Bureau: Diesel \& gasoline consumption (Chinese).http://data.stats.gov.cn/easyquery.htm? $\mathrm{cn}=\mathrm{C} 01$

4. China Standardization Administration Committee: Fuel Consumption Limits for Heavy-Duty Commercial Vehicles: GB 305102018. China Standard Publisher, Beijing (2018)

5. Teng, H., Regner, G., Cowland, C.: Waste heat recovery of heavyduty diesel engines by organic rankine cycle Part II: Working Fluids for WHR-ORC.SAE 2007-01-0543

6. Park, T., Teng, H., Hunter, G., et al.: A rankine cycle system for recovering waste heat from HD diesel engines-experimental results. SAE Technical Paper, 2011-01-1337

7. Park, S.W., Reitz, R.D.: Numerical study on the low emission window of homogeneous charge compression ignition diesel combustion. Combust Sci Technol 179(11), 2279-2307 (2007)

8. Bergman, M., Golovitchev, V.I.: Application of transient temperature vs. equivalence ratio emission maps to engine simulations. SAE Technical Paper, 2007-01-1086

9. Baines, N.C.: Fundamentals of Turbo charging. In: Concepts NREC, 2005

10. Boretti, A.A.: Numerical evaluation of the performance of a compression ignition $\mathrm{CNG}$ engine for heavy duty trucks with an optimum speed power turbine. Int. J. Eng. Technol. Innov. 1(1), 12-26 (2011) 